\title{
The effect of increasing the supply of skilled health providers on pregnancy and birth outcomes: evidence from the midwives service scheme in Nigeria
}

Edward Okeke ${ }^{1 *}$, Peter Glick ${ }^{1}$, Amalavoyal Chari ${ }^{2}$, Isa Sadeeq Abubakar ${ }^{3}$, Emma Pitchforth ${ }^{4}$, Josephine Exley ${ }^{4}$, Usman Bashir ${ }^{3}$, Kun Gu${ }^{1}$ and Obinna Onwujekwe ${ }^{5}$

\begin{abstract}
Background: Limited availability of skilled health providers in developing countries is thought to be an important barrier to achieving maternal and child health-related MDG goals. Little is known, however, about the extent to which scaling-up supply of health providers will lead to improved pregnancy and birth outcomes. We study the effects of the Midwives Service Scheme (MSS), a public sector program in Nigeria that increased the supply of skilled midwives in rural communities on pregnancy and birth outcomes.

Methods: We surveyed 7,104 women with a birth within the preceding five years across 12 states in Nigeria and compared changes in birth outcomes in MSS communities to changes in non-MSS communities over the same period.

Results: The main measured effect of the scheme was a 7.3-percentage point increase in antenatal care use in program clinics and a 5-percentage point increase in overall use of antenatal care, both within the first year of the program. We found no statistically significant effect of the scheme on skilled birth attendance or on maternal delivery complications.
\end{abstract}

Conclusion: This study highlights the complexity of improving maternal and child health outcomes in developing countries, and shows that scaling up supply of midwives may not be sufficient on its own.

Keywords: Health workers, Midwives, Supply, Maternal health, Impact evaluation

Abbreviations: DID, Difference-in-difference; GPS, Global positioning system; MDG, Millennium development goals; MSS, Midwives service scheme; NPHCDA, National primary health care development agency

\section{Background}

One of the major global health challenges of the 21st century is reducing the approximately 3 million newborn deaths, 7 million under-five deaths, and 300,000 maternal deaths that occur globally each year. This health burden is not uniformly distributed: most deaths occur in the poorest regions of the world $-87 \%$ of maternal deaths and about $65 \%$ of neonatal deaths, for example, occur in sub-Saharan Africa and South Asia [1]. Many of

\footnotetext{
* Correspondence: eokeke@rand.org

${ }^{1}$ RAND Corporation, Santa Monica, CA, USA

Full list of author information is available at the end of the article
}

these deaths are believed to be preventable: it has been estimated, for example, that up to a third of maternal deaths, and half of newborn deaths can be prevented by increasing coverage rates for skilled attendance at delivery [2-4].

In many of the countries lagging behind Millennium Development Goal (MDG)-related targets, poor access to skilled health providers, particularly in rural areas, is regarded as one of the main challenges to increasing rates of skilled birth attendance and improving outcomes for children and mothers [5]. Two recent studies have brought this issue into sharp focus by estimating the effect of scaling up access to midwives on maternal and infant health $[6,7]$. Given limited empirical evidence 
regarding the effects of scaling up access to midwives, both studies rely on model-based projections.

In this paper, we present empirical findings from an evaluation of a large-scale program in Nigeria that sought to increase access to midwives in rural communities. This program, known as the Midwives Service Scheme, deployed thousands of midwives to primary health facilities across Nigeria to increase access to skilled care. The stated goal of the program was to double the proportion of births attended by skilled attendants by December 2015. In 2014 we carried out a mixed-methods evaluation to study the impact of the program on use of antenatal care during pregnancy and on skilled birth attendance five years after implementation of the scheme. We also examine effects on maternal delivery complications. This study provides timely evidence to policy makers in developing countries looking to increase coverage of skilled birth attendance and improve maternal and child health outcomes.

\section{Methods}

\section{The Nigerian midwives service scheme}

Every year, more than 50,000 Nigerian women die from pregnancy-related complications. The chance of a woman dying during pregnancy and childbirth in Nigeria is approximately 1 in 30 compared to about 1 in 2,400 in developed countries [8]. Infants also experience poor health outcomes with an estimated 250,000 newborn deaths annually. These high rates of mortality have been attributed in part to low utilization of pregnancy and delivery care: only $39 \%$ of births, for example, are attended by a skilled health provider. In many health facilities across the country, there is a shortage of skilled providers (doctors, nurses and midwives). A survey of primary health facilities in rural communities found that up to half did not have a single midwife [9].

The Midwives Service Scheme (MSS) was introduced in December 2009 to address these challenges. The key feature of the MSS was the recruitment and deployment of unemployed, retired, and newly graduating midwives to government primary health facilities in rural and underserved communities. Participating midwives were recruited through a national recruitment exercise. The scheme was funded by debt relief funds under a 2009 Appropriations Act and was designed to be a collaborative effort between all three tiers of government. The federal government recruited and deployed the midwives, paid them a monthly salary (N30,000 or approximately 150 USD) and supplied clinics with midwifery kits (these kits contain essential items needed for deliveries such as instruments, sutures, gloves, and cord clamps), basic equipment such as blood pressure apparatus and weighing scales, some essential drugs, and facility/community registers for record keeping; state governments paid additional allowances to midwives (N20,000 per month) and provided monitoring and supervision; local governments paid a supplementary allowance of N10,000 and provided free accommodation for the midwives in the local community.

The first phase of the scheme-the subject of our evaluation-rolled out nationally in 652 primary health care facilities in 2009. The distribution of MSS facilities was determined largely by geographic location. States in the northeast and northwest zones (classified as 'very high' maternal mortality zones) were assigned 24 facilities each, states in the north-central and south-south (classified as 'high' mortality zones) were assigned 16 facilities each, and states in the southwest and southeast (classified as 'moderate' mortality zones) were assigned $12 \mathrm{fa}$ cilities each (see Table 1). Each MSS facility was linked to a general hospital that would serve as a referral hospital. Nearly 2,500 midwives in total were deployed in the first phase of the scheme.

\section{Study design}

To identify the effects of the MSS we compared changes in pregnancy and birth outcomes in MSS (intervention) communities to changes in non-MSS (comparison) communities in the same states over the same period i.e., a difference-in-difference design. The comparison group consisted of similar communities (as the intervention communities) that, however, were not enrolled in (an updated version of) the program until three years later; we refer to this as Wave 2. Thus we exploit the fact that there was a window of time within which one group of communities was exposed (Wave 1) but the other was not yet exposed (Wave 2). Both sets of health facilities were selected using the same criteria. Data on pregnancy and birth outcomes were collected retrospectively through a household survey in both sets of communities targeting women who had a recent pregnancy (see next section). A graphical illustration of our study design is provided in Fig. 1.

Two hundred eight MSS communities were randomly selected to participate in the study. To draw the study sample we began by randomly selecting two states in each geopolitical zone (making 12 states in total), and then enrolling all MSS health facilities in the state into the study. We randomly selected an equivalent number of Wave 2 facilities in each state to serve as a comparison group. It is important to clarify that prior to rollout, participating communities

Table 1 Distribution of health facilities

\begin{tabular}{lll}
\hline Region & Number of states/region & Number of clinics/state \\
\hline North-East & 6 & 24 \\
North-West & 7 & 24 \\
North-Central & 7 & 16 \\
South-South & 6 & 16 \\
South-East & 5 & 12 \\
South-West & 6 & 12 \\
\hline
\end{tabular}




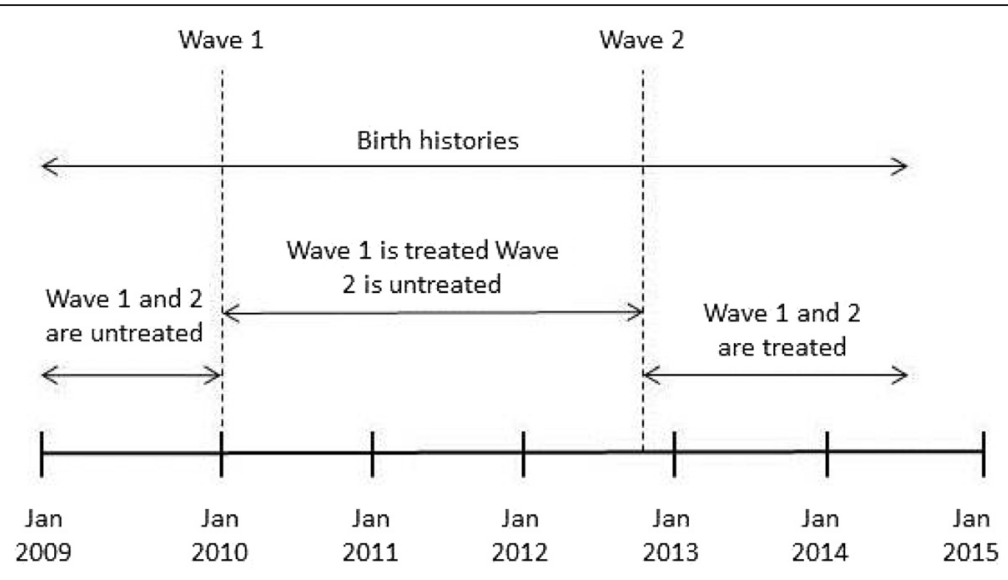

Fig. 1 Graphical illustration of research design

did not have any advance knowledge that they would participate in the scheme. We carried out qualitative interviews and focus groups in three purposively selected states to shed light on program implementation and to provide additional context for the evaluation findings. These results are presented in a companion paper [10].

\section{Data collection}

Institutional Review Boards at RAND, Bayero University Kano, and University of Nigeria Enugu provided ethical review and approval for the study. Data collection took place between June 2014 and January 2015. Since a comprehensive listing of households in each community was unavailable, we randomly generated Global Positioning System (GPS) coordinates within each community using a GPS-enabled tablet and special software and selected the dwelling nearest this point for interview. Twenty households were randomly selected in each community, with the criterion for inclusion that they contained a woman who was pregnant at least once between January 2009 and the date of interview. If there was no eligible household within the dwelling, the interviewer visited the dwelling on either side until one was found. If there were multiple eligible households within the dwelling, one was randomly chosen for interview. All eligible women within each selected household were interviewed. To obtain consent, interviewers read out a statement to study respondents describing the study and any associated risks/benefits of participation. Interviewers checked a box on the consent screen of the tablet to indicate that verbal consent had been provided. In total we interviewed 7,104 women in 368 communities (not all communities selected could be surveyed because of logistical constraints).

The survey instrument included a household module that collected information including dwelling characteristics, source of drinking water, toilet facilities and possession of various assets (these were aggregated into a wealth index using principal component analysis); and an individual module administered to all eligible women. The individual module collected retrospective information about each birth since January 2009 including use of antenatal and postnatal care, place of delivery, and pregnancy and delivery complications such as haemorrhage, fever and convulsions. Respondents were asked about complications during delivery (intrapartum complications) and within six weeks after delivery (postpartum complications). We also carried out a clinic survey in each study clinic (both MSS and non-MSS clinics). Interviewers collected data on clinic characteristics including staffing and availability of supplies from the officer-in-charge (or another knowledgeable individual if the officer-in-charge was unavailable). All interviews were administered face-to-face using Android tablets.

\section{key variables}

Our primary outcomes are antenatal care and skilled birth attendance. We consider the following measures for antenatal care: (1) an indicator for any antenatal care use, (2) an indicator for whether a mother received at least 4 antenatal visits (per World Health Organization recommendations), and (3) an indicator for antenatal care obtained in the study clinic. For skilled birth attendance our measures are: (1) an indicator for whether a birth took place in the study clinic, (2) an indicator for whether the birth took place in any health facility (i.e., was attended), and (3) an indicator for whether a birth was attended by a doctor, nurse or midwife independent of birth location. For both outcomes we look separately at uptake in the study clinic and overall uptake. This allows us to measure any substitution effects i.e., women switching from other sources of formal care to the MSS clinic. Even though the goal of the program was to increase uptake among prior non-users, switching from other sources of formal care to the MSS 
clinic is potentially beneficial if the MSS clinic is closer, thus reducing time and travel costs, and/or if the care offered by MSS midwives is of higher quality relative to existing alternatives.

Our secondary outcomes are maternal birth complications. We look at the probability that a mother experienced at least one of several complications including severe bleeding, convulsions, retained placenta, prolonged labor, loss of consciousness or high fever, either during the delivery (intrapartum complications) or within six weeks of delivery (postpartum complications).

\section{Empirical strategy}

To identify the impact of the MSS, we estimate differencein-difference (DID) models that examine the relative change in outcomes in MSS (intervention) relative to non-MSS (comparison) areas. The basic econometric specification is the following:

$$
y_{i j t}=\alpha+\beta_{1} \text { Treated }_{j}+\beta_{2} \text { Post }_{t}+\beta_{3} \text { Treated }_{j} * \text { Post }_{t}+\eta_{j}+e_{i j t}
$$

$y_{i j t}$ denotes the outcome of interest for birth $i$ in community $j$ in month $t$ (starting in January 2009); Treated $_{j t}$ is an indicator that takes the value 1 if the study clinic in community $j$ is a Wave 1 (MSS) clinic; Post $_{t}$ is a binary indicator that takes the value 1 after the MSS is introduced; $\eta_{j}$ is a community fixed effect; and $e_{i j t}$ is an unobserved error term. In this specification our interest centers on the coefficient $\beta_{3}$, which measures the differential change in the outcome in intervention communities relative to comparison communities. We include controls for gender of the baby, an indicator for a multiple birth, marital status, mother's education and religion, the mother's age at the time of the birth, an indicator equal to one if the woman reported at least one complication during pregnancy, and household wealth (quintiles of an asset-based wealth index derived using principal component analysis). Standard errors are clustered at the level of the community given correlation in the outcomes within this level.

The main assumption required for identifying causal effects in the DID model is that the evolution of outcomes in intervention areas would have followed the same pattern as in comparison areas in the absence of the treatment (this is known as the parallel trends assumption). While this counterfactual cannot be known, we can test whether this assumption holds for each of the outcome variables of interest prior to the introduction of the program. Finding that the trends are the same in intervention and control areas before the program adds to confidence in the assumption that (nonprogram) trends are the same following program introduction as well. We estimate the following regression specification:

$$
y_{i j t}=\alpha+\beta \text { Treated }_{j}+\gamma t+\delta \text { Treated }_{j} * t+\eta_{j}+e_{i j t}
$$

where the regression sample is restricted to baseline births (those that occurred before introduction of the MSS), $t$ denotes monthly pre-trends, and where interest centers on the interaction coefficient $\delta$ (the parallel trends assumption implies that $\delta=0$ ).

\section{Results}

All data were analyzed using Stata 12 software. The survey sample consists of 9,475 births born to 7,104 women over the period 2009-2014, of which 4,746 (50.33\%) occurred in MSS (intervention) areas. We exclude births occurring after women in the comparison group became exposed to the intervention, leaving us with 5,295 births taking place between January 2009 and May 2012. Table 2 summarizes the variables used in the analysis at baseline, and tests for balance across intervention and comparison areas. Even though the DID identification strategy does not require it (as noted earlier, the key assumption involves equivalence of trends not levels), it is reassuring to note that the outcome variables as well as the covariates are relatively well balanced at baseline. In Table 3 , we test the parallel trends assumption for each of the outcome variables of interest, using the specification shown in (2). As Table 3 shows, the null hypothesis cannot be rejected for any of the outcome variables, which lends credence to the empirical strategy.

Table 4 presents the DID results for each of the measures of antenatal care. For each outcome, we report the average effect of the MSS [this is the coefficient on the interaction of Treated and Post from specification (1)]. We then disaggregate this average effect into effects in each year of the program to examine whether the effects of the scheme vary over time. The impact of the scheme might increase over time if it takes time for information about midwife availability in the clinic to spread through the community or if it takes time to gain the trust of the community. Conversely it might decrease if over time the availability of midwives in the clinic becomes compromised. We present effects for Year 1, Year 2, and Year 3 of the program after which the comparison group becomes exposed.

The average effect in Table 4 indicates a small positive impact of the program on antenatal care although this result is not statistically significant. We see, however, that this average effect obscures significant variation over time. Row 2 indicates that the rate of antenatal care usage at MSS clinics increased by about 7.3 percentage points (CI: 0.3 to $14.2 \%$ ) in the first year of the program (starting from a baseline rate of $62.2 \%$ ), but thereafter 
Table 2 Baseline characteristics and balance

\begin{tabular}{|c|c|c|c|c|c|}
\hline & Contro & & Interve & & \\
\hline & Mean & Std dev & Mean & Std dev & $p$-value \\
\hline Any antenatal care & 0.801 & 0.400 & 0.834 & 0.372 & 0.281 \\
\hline $4+$ antenatal visits & 0.504 & 0.500 & 0.506 & 0.500 & 0.953 \\
\hline Antenatal care in study clinic & 0.539 & 0.499 & 0.622 & 0.485 & 0.054 \\
\hline Intra-partum complications & 0.064 & 0.301 & 0.048 & 0.240 & 0.349 \\
\hline Post-partum complications & 0.044 & 0.233 & 0.042 & 0.228 & 0.870 \\
\hline Institutional delivery & 0.541 & 0.499 & 0.570 & 0.496 & 0.496 \\
\hline Delivered in study clinic & 0.344 & 0.475 & 0.420 & 0.494 & 0.058 \\
\hline Skilled birth attendance & 0.533 & 0.499 & 0.540 & 0.499 & 0.876 \\
\hline Breastfed for 6 months & 0.417 & 0.493 & 0.376 & 0.485 & 0.342 \\
\hline Married & 0.869 & 0.338 & 0.876 & 0.329 & 0.761 \\
\hline Age of mother & 31.79 & 40.70 & 29.31 & 6.598 & 0.172 \\
\hline Illiterate & 0.542 & 0.499 & 0.564 & 0.496 & 0.649 \\
\hline Muslim & 0.591 & 0.492 & 0.574 & 0.495 & 0.773 \\
\hline Wealth index & 2.934 & 1.468 & 2.936 & 1.431 & 0.989 \\
\hline Male child & 0.512 & 0.500 & 0.532 & 0.499 & 0.503 \\
\hline Multiple birth & 0.029 & 0.168 & 0.024 & 0.153 & 0.724 \\
\hline Low risk (no problems during pregnancy) & 0.828 & 0.378 & 0.833 & 0.374 & 0.870 \\
\hline
\end{tabular}

Note: $p$-values correspond to tests for differences in means, and allow for observations to be correlated within communities

we are not able to find any program effect. There is a less precisely estimated 5-percentage point increase (CI: -0.2 to $10.2 \%$ ) in the overall rate of antenatal care use, but little evidence of an increase in the number of visits as measured by the rate of four or more antenatal visits.

In Fig. 2, we plot the coefficients (and associated $95 \%$ confidence intervals) from a more refined specification that allows program effects to vary by quarter. We find that antenatal care usage at the study clinic rose by more than $10 \%$ age points in the first three quarters following introduction of MSS, but thereafter dropped off. The graphs also show that overall use of antenatal care (not restricting to care in the study clinic) increased on both

Table 3 Testing for differential pre-trends in outcome variables

\begin{tabular}{lllll}
\hline & Number & $\delta(95 \% \mathrm{Cl})$ & $p$-value \\
\hline Antenatal care in study clinic & 1094 & 0.002 & $(-0.020,0.025)$ & 0.854 \\
Any antenatal care & 1091 & 0.009 & $(-0.011,0.029)$ & 0.371 \\
4+ antenatal visits & 1094 & 0.003 & $(-0.021,0.028)$ & 0.783 \\
Delivery in study clinic & 1094 & 0.004 & $(-0.019,0.026)$ & 0.761 \\
Institutional delivery & 1094 & 0.005 & $(-0.018,0.028)$ & 0.684 \\
Skilled birth attendance & 1094 & -0.001 & $(-0.023,0.021)$ & 0.916 \\
Intra-partum complications & 1094 & 0.014 & $(-0.004,0.032)$ & 0.126 \\
Post-partum complications & 1094 & 0.008 & $(-0.005,0.021)$ & 0.213 \\
\hline Sdenote
\end{tabular}

$\delta$ denotes the differential linear trend in intervention communities relative to comparison communities over the period prior to the start of the MSS. The regression specification controls for community fixed effects. Standard errors in parentheses are clustered at the community level
Table 4 Estimated effects of MSS on antenatal care utilization

\begin{tabular}{|c|c|c|c|c|}
\hline & Number & $\beta(95 \% \mathrm{Cl})$ & $p$-value & $\% \mathrm{D}$ \\
\hline \multicolumn{5}{|c|}{ Antenatal care in study clinic } \\
\hline Average effect & 5295 & $0.023(-0.038,0.084)$ & 0.459 & 0.037 \\
\hline Year 1 & 5295 & $0.073^{* *}(0.003,0.142)$ & 0.042 & 0.117 \\
\hline Year 2 & 5295 & $-0.007(-0.078,0.063)$ & 0.838 & -0.011 \\
\hline Year 3 & 5295 & $0.003(-0.076,0.082)$ & 0.940 & 0.005 \\
\hline
\end{tabular}

Any antenatal care

$\begin{array}{lllll}\text { Average effect } & 5287 & 0.018(-0.025,0.061) & 0.416 & 0.022 \\ \text { Year 1 } & 5287 & 0.050^{*}(-0.002,0.102) & 0.059 & 0.060 \\ \text { Year 2 } & 5287 & -0.005(-0.056,0.045) & 0.835 & -0.006 \\ \text { Year 3 } & 5287 & 0.009(-0.047,0.064) & 0.763 & 0.011 \\ \text { 4+ antenatal visits } & & & & \\ \text { Average effect } & 5295 & -0.006(-0.075,0.062) & 0.857 & -0.012 \\ \text { Year 1 } & 5295 & 0.028(-0.047,0.104) & 0.463 & 0.055 \\ \text { Year 2 } & 5295 & -0.036(-0.119,0.048) & 0.402 & -0.071 \\ \text { Year 3 } & 5295 & -0.011(-0.101,0.080) & 0.815 & -0.022\end{array}$

$\beta$ denotes the estimated effect of the MSS program, and is obtained using a differences-in-differences specification that includes month of birth and community fixed effects and controls for maternal and child characteristics. \%D expresses the estimated program effect as a percentage of the baseline average of the outcome variable. Standard errors in parentheses are clustered at the community level

${ }^{* *} p<0.05,{ }^{*} p<0.1$ 

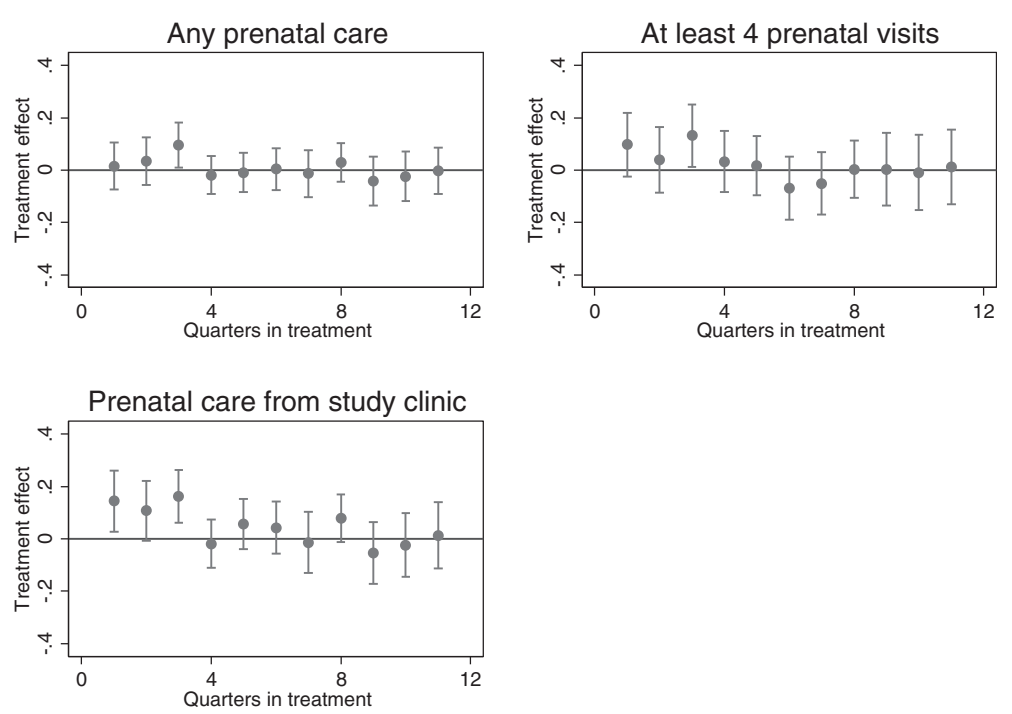

Fig. 2 Program effects over time: Antenatal care

the extensive (i.e. rate of any antenatal care) and intensive margins (rate of four or more antenatal visits) during this period, but thereafter declined. From this we conclude that the MSS had a significant, but somewhat short-lived, impact on antenatal care use.

Table 5 presents the DID results for each of the measures of skilled birth attendance. Again we report average effects and effects over time. Overall, the MSS appears to have had little impact on delivery in the study clinic (Estimate: $-0.7 \%$; CI: -7.0 to $5.5 \%$ ), institutional delivery (Estimate: $-1.6 \%$; CI: -7.4 to $4.1 \%$ ), or skilled birth attendance (Estimate: $-0.16 \%$; CI: -5.6 to $5.5 \%$ ). The confidence intervals are tight enough that we can rule out economically significant effects on any of the outcomes. This conclusion is not significantly modified if we decompose program effects by year or quarter (see Fig. 3).

In Table 6 we examine the impact of the MSS on our secondary outcome, maternal complications. Not surprisingly given the lack of major impacts on antenatal care or birth attendance, we find no evidence that the MSS reduced the incidence of intrapartum complications (Estimate: $1.2 \%$; CI: -2.8 to $5.1 \%$ ) or postpartum complications (Estimate: $0.2 \%$; CI: -3.3 to $3.8 \%$ ).

\section{Discussion}

The results in the previous section show that the MSS had smaller than anticipated effects (relative to the ambitious program goals). The main measured effect of the program is that it increased the use of antenatal care, with gains concentrated in the first year of the program. The pattern of results indicate that the MSS did not simply result in women changing where they attended antenatal care, as would have been the case if antenatal care use at the study clinic increased without an increase in the overall rate of antenatal care use. Given that the overall rate of antenatal care use increased, albeit by a smaller fraction than the observed increase in the MSS clinics, we conclude that the MSS was successful in inducing some women into antenatal care who would not have used care otherwise. However, we find no evidence of an increase in institutional deliveries or skilled birth attendance, even though

Table 5 Estimated effects of MSS on institutional delivery and skilled birth attendance

\begin{tabular}{|c|c|c|c|c|}
\hline & Number & $\beta(95 \% \mathrm{Cl})$ & $p$-value & $\% \mathrm{D}$ \\
\hline \multicolumn{5}{|c|}{ Delivery in study clinic } \\
\hline Average effect & 5295 & $-0.007(-0.070,0.055)$ & 0.815 & -0.017 \\
\hline Year 1 & 5295 & $-0.008(-0.081,0.065)$ & 0.833 & -0.019 \\
\hline Year 2 & 5295 & $0.005(-0.067,0.078)$ & 0.883 & 0.012 \\
\hline Year 3 & 5295 & $-0.022(-0.099,0.055)$ & 0.567 & -0.052 \\
\hline \multicolumn{5}{|c|}{ Institutional delivery } \\
\hline Average effect & 5295 & $-0.016(-0.074,0.041)$ & 0.574 & -0.028 \\
\hline Year 1 & 5295 & $-0.035(-0.104,0.035)$ & 0.331 & -0.061 \\
\hline Year 2 & 5295 & $0.000(-0.066,0.066)$ & 0.991 & 0.000 \\
\hline Year 3 & 5295 & $-0.016(-0.085,0.053)$ & 0.657 & -0.028 \\
\hline \multicolumn{5}{|c|}{ Skilled birth attendance } \\
\hline Average effect & 5295 & $-0.000(-0.056,0.055)$ & 0.987 & 0.000 \\
\hline Year 1 & 5295 & $-0.014(-0.081,0.054)$ & 0.686 & -0.026 \\
\hline Year 2 & 5295 & $0.025(-0.041,0.090)$ & 0.458 & 0.046 \\
\hline Year 3 & 5295 & $-0.015(-0.084,0.053)$ & 0.665 & -0.028 \\
\hline
\end{tabular}

$\beta$ denotes the estimated effect of the MSS program, and is obtained using a differences-in-differences specification that includes month of birth and community fixed effects and controls for maternal and child characteristics. \%D expresses the estimated program effect as a percentage of the baseline average of the outcome variable. Standard errors in parentheses are clustered at the community level 

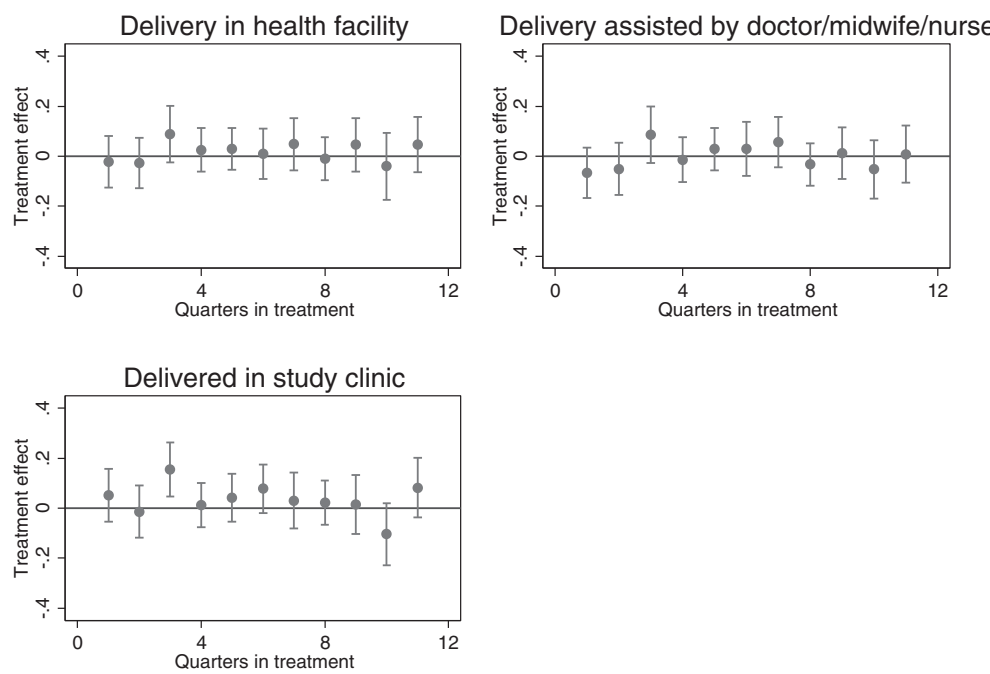

Fig. 3 Program effects over time: Delivery

this was the primary objective of the scheme. Our confidence intervals allow us to rule out effects larger than about 5.5 percentage points (or about 10 percent of the baseline mean).

The fact that there were some positive impacts at the beginning of the scheme that appeared to erode over time may indicate that the effectiveness of the program was compromised by operational challenges that emerged over time. An in-depth look at the implementation of the scheme [10], indicates that problems such as irregular payment of midwife salaries, and inadequate provision of accommodation, affected availability of midwives in the clinics and contributed to long-run difficulties in retaining midwives in the scheme. However this does not explain why there was no effect on skilled birth

Table 6 Estimated effects of MSS on maternal complications

\begin{tabular}{|c|c|c|c|c|}
\hline & Number & $\beta(95 \% \mathrm{Cl})$ & $p$-value & $\% \mathrm{D}$ \\
\hline \multicolumn{5}{|c|}{ Intra-partum complications } \\
\hline Average effect & 5295 & $0.012(-0.028,0.051)$ & 0.556 & 0.250 \\
\hline Year 1 & 5295 & $0.003(-0.044,0.045)$ & 0.912 & 0.063 \\
\hline Year 2 & 5295 & $0.014(-0.035,0.063)$ & 0.577 & 0.292 \\
\hline Year 3 & 5295 & $0.020(-0.033,0.073)$ & 0.466 & 0.417 \\
\hline \multicolumn{5}{|c|}{ Post-partum complications } \\
\hline Average effect & 5295 & $0.002(-0.033,0.038)$ & 0.891 & 0.048 \\
\hline Year 1 & 5295 & $-0.014(-0.053,0.024)$ & 0.469 & -0.333 \\
\hline Year 2 & 5295 & $0.010(-0.038,0.052)$ & 0.660 & 0.238 \\
\hline Year 3 & 5295 & $0.013(-0.037,0.063)$ & 0.612 & 0.310 \\
\hline
\end{tabular}

$\beta$ denotes the estimated effect of the MSS program, and is obtained using a differences-in-differences specification that includes month of birth and community fixed effects and controls for maternal and child characteristics. \%D expresses the estimated program effect as a percentage of the baseline average of the outcome variable. Standard errors in parentheses are clustered at the community level attendance, even in the first year of the program. Our data suggest that part of the reason for this is that other dimensions of service quality did not improve, which deterred uptake [10]. For example, data from the clinic survey suggest that clinic infrastructure in many cases remained poor, as did availability of drugs and supplies. Only $44 \%$ of facilities visited received a rating of "good" by project staff regarding the physical condition of the building [options were poor (requires major rehabilitation), fair (requires minor rehabilitation), and good (requires no rehabilitation)]. Lack of electricity and water were also problems: $35 \%$ of MSS clinics in the clinic survey reported having no electricity. Availability of essential medicines and basic equipment was poor. We assigned clinics a score of one for each piece of equipment that was functional, zero if not. The median score was 13 out of 22 . With regards to essential medicines, on average, clinics had only about half of these medicines in stock, and $21 \%$ of clinics did not have availability of any of the drugs.

We also find some suggestive evidence that that demandside barriers such as low perceived need for services and lack of transportation to clinics continued to play an important role (the revised iteration of the scheme sought to address this constraint by including a conditional cash transfer to households to encourage utilization) [11]. For example, in our survey we asked women who gave birth at home why they did not opt for a facility birth, and for $70 \%$ of births that did not take place in a health facility, the mother reported that the reason was because it was "not necessary". In contrast only $4 \%$ and $<1 \%$ of the time did the mother give "facility not open" and "no female provider" as the reason why. This suggests that women did not consider a facility birth to be a high priority.

This study contributes to a growing literature evaluating the effects of policies and programs designed to increase 
use of maternal and child health services in developing countries. Much of this literature has focused on demandside initiatives such as conditional cash transfers [12, 13], transportation subsidies [14], and voucher schemes [15-17]; supply-side studies are considerably less common. [18] Limited availability of skilled providers, particularly in rural areas, is thought to be an important constraint but there is little empirical research evaluating the effects of scaling up access to providers. Frankenberg et al. [19], one of the few examples, find weak evidence that the village midwife programme in Indonesia increased use of antenatal care and the likelihood of delivering with the assistance of a medically trained provider. Fauveau et al. [20] study a similar midwife program in Bangladesh and find that many home births were still not attended by midwives. The present study is largely consistent with this work in finding small effects of the Midwifery Scheme in Nigeria and highlights the challenge of improving maternal and child outcomes in developing countries.

This study has several limitations. First, as the evaluation was carried out ex-post it presented a number of challenges. For example, though some data were collected at baseline from MSS communities, there was no comparison group at baseline. As such, we do not have a baseline and follow-up in the classical sense; our birth panel is constructed retrospectively. Our design relies on similar trends in intervention and comparison communities, and we attempt to validate this assumption by examining trends in the pre-period. We are not able to reject the null of similarity, but we add the caveat that we have about 11 months of pre-data. A longer pre-period would have been desirable, allowing for a stronger test, but would have meant extending the recall period beyond five years (we followed the widely used Demographic and Health Surveys in keeping the recall period to the last five years). If the underlying assumptions are met, then this strategy provides robust estimates of the effect of the program, but readers should interpret these estimates with this caveat in mind. Second, our approach relies on retrospective information collected from women via a survey, raising the potential problem of accuracy of recall. This is unlikely to be a major concern for our primary outcomes, antenatal care and place of birth/skilled birth attendance, but may be a concern for delivery complications [21, 22]. If the measurement error in the dependent variable is classical (to the extent that it is present) then the estimate of program effects is unbiased (although the standard errors would be larger), but if it is correlated with the explanatory variables then the estimates may be biased [23]. Given this, the results for maternal complications (our secondary outcome) should be interpreted cautiously. However, we note that in developing country settings where a large fraction of births occur outside health institutions, survey data are usually the only option as birth registration data, where available, are notoriously incomplete [24].

\section{Conclusions}

Poor access to skilled health providers, particularly in rural areas, is regarded as one of the main challenges to increasing rates of skilled birth attendance in poor countries. Given the dearth of empirical evidence, researchers have attempted to use models to project the effects of scale-up. Homer et al. [6], for example, estimate that a modest increase in coverage of midwifery could potentially avert $30 \%$ of maternal deaths and half of neonatal deaths. The results in this paper reinforce the need for caution in generalizing from these estimates. As this evaluation shows, scaling up the supply of midwives in the real world is a complex undertaking and may not translate into the desired outcomes. One of the lessons of this evaluation is that increasing the supply of midwives, by itself, may not be a sufficient condition for increasing skilled birth attendance. Other interventions targeting other aspects of service quality such as improving clinic infrastructure and ensuring that clinics have adequate equipment and supplies, strengthening incentives for health providers to deliver high quality care, and tackling demand-side barriers will likely prove necessary.

\section{Acknowledgments \\ We are grateful to Dr. Muhammad Ali Pate, the former Minister of State for Health in Nigeria and former Executive Director of the National Primary Health Care Development Agency, Dr. Ado Muhammad, the current Executive Director of the National Primary Health Care Development Agency, and Dr. Nnenna Ihebuzor, the Director, Primary Health Care Systems Development for their support in carrying out this evaluation. We are also grateful to the many other staff at the NPHCDA who patiently answered our questions and provided helpful information. We thank especially Mrs. Ify Onwudinjo, Dr. Lekan Olubajo, and Dr. Usman Abdulkadir. We received many helpful comments and contributions from participants at our workshops in Abuja for which we are grateful. Finally we thank all the field coordinators, supervisors and data collectors that helped to carry out the study and the thousands of study participants who graciously gave of their time.}

\section{Funding}

This study was funded by the International Initiative for Impact Evaluation (3ie) through Grant No. OW4/1225. The sponsors of the study had no role in study design, data collection, data analysis, data interpretation, or writing of the report.

\section{Availability of data and materials \\ The data that support the findings of this study are available from the corresponding author upon reasonable request.}

\section{Authors' contributions}

EO devised the study, wrote the first and final drafts of the article, and was responsible for overall leadership of the project. AC led the econometric modeling and analysis, and contributed to the writing. PG contributed to the design of the study, interpretation of the findings and writing of the paper. $I A$, UB and $O O$ led the data collection and contributed to the interpretation of the results. EP and JE contributed to the design of the study, data analysis and interpretation of the study findings and writing of the paper. KG contributed to data analysis. All authors helped to interpret the results and undertook reviews and revisions of the paper. All authors read and approved the final manuscript. 


\section{Competing interests}

Dr. Abubakar has served as a consultant to the National Primary Health Care Development Agency. All other authors declare no competing interests.

\section{Consent for publication}

Not applicable.

\section{Ethics approval and consent to participate}

Institutional Review Boards at RAND, Bayero University Kano, and University of Nigeria Enugu reviewed and approved the study protocol. Informed consent was obtained from all participating study subjects.

\section{Author details}

'RAND Corporation, Santa Monica, CA, USA. ${ }^{1}$ University of Sussex, Brighton, UK. ${ }^{3}$ Bayero University Kano, Kano, Nigeria. ${ }^{4}$ RAND Europe, Cambridge, UK. ${ }^{5}$ University of Nigeria Enugu, Enugu, Nigeria.

Received: 7 August 2015 Accepted: 17 August 2016

Published online: 23 August 2016

\section{References}

1. Wang W, Alva S, Wang S, Fort A. Levels And Trends In The Use Of Maternal Health Services. In: Developing Countries. DHS Comparative Reports No. 26. Calverton: ICF Macro; 2011.

2. Bhutta ZA, Das JK, Bahl R, et al. Can available interventions end preventable deaths in mothers, newborn babies, and stillbirths, and at what cost? Lancet. 2014;384(9940):347-70.

3. Goldie SJ, Sweet S, Carvalho N, Natchu UCM, Hu D. Alternative Strategies to Reduce Maternal Mortality in India: A Cost-Effectiveness Analysis. PLoS Med. 2010;7(4):e1000264.

4. Graham WJ, Bell JS, Bullough CHW. Can skilled attendance at delivery reduce maternal mortality in developing countries? Studies Health Service Organisation Policy. 2001;17:97-129.

5. Koblinsky M, Matthews Z, Hussein J, et al. Going to scale with professional skilled care. Lancet. 2006;368(9544):1377-86.

6. Homer CS, Friberg IK, Dias MA, et al. The projected effect of scaling up midwifery. Lancet. 2014;384(9948):1146-57.

7. Bartlett L, Weissman E, Gubin R, Patton-Molitors R, Friberg IK. The impact and cost of scaling up midwifery and obstetrics in 58 low- and middleincome countries. PLoS One. 2014;9(6):e98550.

8. Gill K, Pande R, Malhotra A. Women deliver for development. Lancet. 2007;370(9595):1347-57.

9. National Primary Care Development Agency (NPHCDA). Midwives Service Scheme - Baseline Survey Report. 2010.

10. Okeke EN, Pitchforth E, Exley J, Glick P, Abubakar IS, Chari AV, Bashir U, Gu K, Onwujekwe O. The complexity of increasing access to skilled care: Evidence from the implementation of the Nigerian Midwives Service Scheme. Working Paper, RAND Corporation

11. Okoli U, Morris L, Oshin A, Pate MA, Aigbe C, Muhammad A. Conditional cash transfer schemes in Nigeria: potential gains for maternal and child health service uptake in a national pilot programme. BMC Pregnancy Childbirth. 2014;14(1):408

12. Lim SS, Dandona L, Hoisington JA, James SL, Hogan MC, Gakidou E. India's Janani Suraksha Yojana, a conditional cash transfer programme to increase births in health facilities: an impact evaluation. Lancet. 2010;375(9730):2009-23.

13. Powell-Jackson T, Hanson K. Financial incentives for maternal health: Impact of a national programme in Nepal. J Health Econ. 2012;31(1):271-84.

14. Ekirapa-Kiracho E, Waiswa $P$, Rahman M, et al. Increasing access to institutional deliveries using demand and supply side incentives: early results from a quasiexperimental study. BMC Int Health Human Rights. 2011;11 Suppl 1:S11.

15. Bellows NM, Bellows BW, Warren C. Systematic Review: The use of vouchers for reproductive health services in developing countries: systematic review. Trop Med Int Health. 2011;16(1):84-96.

16. Nguyen HTH, Hatt L, Islam M, et al. Encouraging maternal health service utilization: An evaluation of the Bangladesh voucher program. Soc Sci Med. 2012;74(7):989-96.

17. Obare F, Warren C, Njuki R, et al. Community-level impact of the reproductive health vouchers programme on service utilization in Kenya. Health Policy Plan. 2013;28(2):165-75.

18. Kumar S, Dansereau E. Supply-Side Barriers to Maternity-Care in India: A Facility-Based Analysis. PLoS One. 2014;9(8):e103927.
19. Shankar A, Sebayang S, Guarenti L, et al. The village-based midwife programme in Indonesia. Lancet. 2008;371(9620):1226-9.

20. Fauveau V, Stewart K, Khan SA, Chakraborty J. Effect on mortality of community-based maternity-care programme in rural Bangladesh. Lancet. 1991;338(8776):1183-6.

21. Stewart MK, Festin M. Validation study of women's reporting and recall of major obstetric complications treated at the Philippine general hospital. Int J Gynecol Obstet. 1995;48(Supplement):S53-66.

22. Sloan NL, Amoaful E, Arthur P, Winikoff B, Adjei S. Validity of women's selfreported obstetric complications in rural Ghana. J Health Popul Nutr. 2001;19(2):45-51.

23. Wooldridge J. Econometric Analysis of Cross Section and Panel Data. Cambridge: MIT Press; 2002.

24. Heap S, Cody C. Children, Rights and combating statelessness: Plan's Experience of Improving Birth Registration. A paper presented at the Children without a State: A Human Rights Challenge Conference. Boston: Harvard University; 2008

\section{Submit your next manuscript to BioMed Central and we will help you at every step:}

- We accept pre-submission inquiries

- Our selector tool helps you to find the most relevant journal

- We provide round the clock customer support

- Convenient online submission

- Thorough peer review

- Inclusion in PubMed and all major indexing services

- Maximum visibility for your research

Submit your manuscript at www.biomedcentral.com/submit 